\title{
Failure of Interpretation: Semiotic Representations in Fractional Problem Solving
}

\author{
Christine Wulandari Suryaningrum ${ }^{1}$, Purwanto ${ }^{2}$, Subanjii ${ }^{3}$, Hery Susanto ${ }^{4}$ \\ ${ }^{1}$ Department of Mathematics Education, University Muhammadiyah Jember, \\ Jember, Indonesia \\ E-mail: christine.wulandari@unmuhjember.ac.id \\ ${ }^{2}$ Department of Mathematics Education, University Negeri Malang, \\ Malang, Indonesia \\ E-mail: purwanto.fmipa@um.ac.id \\ ${ }^{3}$ Department of Mathematics Education, University Negeri Malang, \\ Malang, Indonesia \\ E-mail: subanji.fmipa@um.ac.id \\ ${ }^{4}$ Department of Mathematics Education, University Negeri Malang, \\ Malang, Indonesia \\ E-mail: hery.susanto..fmipa@um.ac.id
}

\begin{abstract}
Semiotics is the study of signs. Signs are the result of thoughts used to find mathematical relationships with realworld objects and to represent abstract mathematical concepts. The purpose of this qualitative research is to analyze the failure of interpretation in the semiotic representation of elementary school students in solving fraction problems. To the subject given one problem-solving problem. From the results of the study, showing the subject uses visual representation. The subject solved the problem using pictures. The steps taken by the subject in solving the problem are correct but the subject is wrong in drawing the final conclusion that each Aqla sister gets a third portion of the pizza. Failure to interpret occurs when the research subject does not see the pizza picture given to Aqla's grandfather. The subject failed in interpreting the semiotic representation of a picture of half a pizza given to grandfather and half a pizza given to Aqla's three siblings. This happened because the subject ignored the pizza picture that was given to Aqla's grandfather. The loss of subject attention to the half pizza picture of students accustomed to being given instructions by the teacher in solving problems
\end{abstract}

Keywords: Semiotic representation, problem-solving, fractions

\section{Introduction}

Semiotics is the study of signs. A sign is a physical form that can be captured by the five human senses and can represent other things outside the sign itself [1]. Sign formation is used to communicate information. Semiotics and representations are important things in mathematics. Abstract mathematical concepts will be easily understood if the concepts are represented through symbols or signs. This is in accordance with [2], [3] which states that in mathematics learning activities students can interpret and transform signs to develop mathematical knowledge. Something important in making a sign is how meaning arises from a sign when the sign is used to communicate [1]. In learning mathematics, one needs signs and representations. Signs are used to thinking about mathematical relationships 
with real-world objects. Signs are the result of thoughts used to produce new signs. A sign is a representation of the object. Interpretation is a thought or notation to represent an object. Each sign can act as an object or as an interpreter of other signs [4], [5].

The ability of student representation is an important thing that needs attention in mathematics learning. The representation will provide multiple perceptions so that children will be able to develop their thought processes. With representation, problems that originally seemed difficult and complicated can be seen more easily and simply. [6] states that using multiple representations provides advantages because the use of multiple representations avoids the limitations of one type of representation and constructs new representations, which are clearer and more useful for the problemsolving process. The ability of students to represent a mathematical problem to various forms of representation can provide opportunities for students to be able to solve the same problem in different ways, so students are not only focused on one answer and one representation [7]. The representation will help students organize their thinking processes. In this case, representation helps students in arranging abstract mathematical ideas to be more concrete and real. The use of multiple representations in mathematics learning can provide retention of understanding mathematical material and can increase students' interest in mathematics [6].

The ability of multiple mathematical representations is the ability to use various mathematical expressions to explain mathematical ideas, translate between mathematical expressions, and interpret mathematical phenomena with various mathematical expressions, namely visual (graphs, tables, diagrams, and pictures); symbolic (mathematical statement / mathematical notation, numeric or algebraic symbol); verbal (words or written text) [8]-[10]. The forms of indicators of visual representations (graphs, tables, diagrams, and pictures) are: (a) Presenting data or information from a representation into the representation of diagrams, graphs or tables, (b) Using visual representations to solve problems, (c) Resolving problems withdrawing geometric patterns, (d) Creating geometric shapes to clarify the problem and facilitate its resolution [7]. Indicator forms of symbolic representation (mathematical statements / mathematical notation, numeric or algebraic symbols) are (a) Making mathematical expressions or expressions of a given problem, (b) Making a conjecture of a number pattern, (c) Solving problems of an expression mathematically using algebraic symbols. The forms of indicators of verbal representations (words or written text) are (a) Creating a problem situation based on the data or representation provided, (b) Writing the interpretation of a representation, (b) Arranging a story in accordance with a representation presented, (c) Write down the steps of problem-solving with written words or text, (d) Create and answer questions using written words or text.

In problem-solving, the representation of mathematical concepts plays a very important role, especially in transforming abstract mathematical ideas into real mathematical concepts [11]. With representation, problems that originally looked difficult and complicated can be seen more easily and simply [12]. Representation of mathematical concepts can be in the form of pictures, tables, symbols, and words. Mathematics is abstract ideas, so to make it easier and clearer in solving mathematical problems, representation is very important, namely to change abstract ideas or ideas into real concepts, for example with pictures, symbols, words, graphics, tables and others [13]. Thus, if students have access to the representations of the ideas displayed, then they will have a set of tools that significantly increases their capacity in mathematical thinking and are able to solve mathematical problems. This is supported by the opinion [12], [14] which states that the ability of students to represent a mathematical problem to various forms of representation can provide opportunities for students to be able to solve the same problem in different ways.

Research on semiotics in problem-solving has been carried out by several experts, among them are the results of research [15] showing the semiotic and semantic features of mathematical tasks arranged in the course of teaching mathematics for the education of elementary school students. The results of the study [16] state that students can understand the material that is not yet understood with semiotic representations. The results of the study [17] reported that when elementary school students were given a number of 8060 , there were two different interpretations. The first interpretation shows that the writing is read as a sign/representamen for the object "two digits two digits", namely 80 and 60 . The second interpretation of students sees the object "one digit four digits", ie 8060. Research results [18] report that semiotic sources are used by a sixth-grade teacher who is experienced when 
his students complete math assignments involving written texts and two inscriptions namely drawings and diagrams.

The purpose of this study is to analyze the failure of interpretation in the semiotic representation of elementary school students in solving fraction problems. Based on observations in one private school in Jember Regency when the teacher asks students to take a stick and divide it into 2 parts. The teacher says to divide the stick into two equal parts, then the stick part is (half). In the activity students experience confusion and ask, isn't it after cutting the stick into 2? From these learning activities illustrated that children have difficulty understanding the concept of fractions

\section{Method}

This type of research is qualitative research with case study case analysis. Qualitative research (qualitative research) is research aimed at describing and analyzing phenomena, events, social activities, attitudes, beliefs, perceptions, and thoughts of individuals individually or in groups [19]. Qualitative research does not use statistics. Data from research results are obtained directly from research subjects, such as participant observation, in-depth interviews, and document studies so that researchers get answers as they are from the research subjects.

The subject of the study was given one problemsolving problem which was presented in the form of a story problem. The matter of a story given to the subject aims to improve the quality of arithmetic. This is in accordance with the opinions [20], [21] suggest that successful word problem solving can lead to increased quality of computation skills in middle school students. The problems given to the subject are as follows.

"Aqla has one pizza. Half the pizza was given to his grandfather. The rest is divided among three younger siblings. How many pizzas does each Aqla sister get?"

The location in this study was in one private elementary school in Jember Regency. The selection of subjects is based on field observational data and considerations from the teacher. The research was carried out through three stages, namely the planning stage, the implementation phase and the report writing stage. Activities carried out at the planning stage are (a) compiling indicators of mathematical representation ability, (b) preparing supporting instruments, (c) determining the location of research. At the implementation stage, the activities carried out are: (a) selecting research subjects, (b) implementing Fractional Learning material, (c) collecting mathematical representation data, (d) data analysis. At the writing stage, the activities carried out are: (a) drawing conclusions and (b) writing the results of research.

The instrument used in this study was that researchers acted as key instruments. While the supporting instruments are (a) video recording and problem-solving problems. Data collection is done in four ways, namely (a) Direct Observation, (b) Thinking out loud (Think Aloud), (c) Introspection, namely questions raised by researchers to request an explanation of the thought processes that have been carried out by the subject and voiced but the researcher does not understand the purpose of think aloud, (d) interview. From the data obtained during the course of the research, the researcher can analyze the data by stages (a) transcribing collected video data, (b) reducing data, (c) describing data and (d) making conclusions.

\section{Result and Discussion}

\subsection{Result}

The selection of research subjects is based on the results of field observations and input from the teacher. One research subject was found. The subject chosen has high mathematical abilities. In understanding a subject matter, the subject listens to the teacher's explanation while drawing in his book. Subjects tend to work on solving math problems using pictures.

In solving problems, researchers asked subjects to read and understand the problems given. From the observations, the subject reads the problem repeatedly. The way the subject reads the problem is different between reading the first question and reading the next question. When you first read the problem, the subject reads noiselessly. But when reading the questions for the second time, the subject reads the questions in a low and fast voice. Whereas when repeating reading the question the third time the subject reads the question in a soft and slow voice and the forefinger draws a pizza shape on the table. The subject tried to understand the problem. The subject seemed confused in understanding the problem. The subject takes 15 minutes to understand the meaning of the problem. After seeing that there is an expression of understanding with what is meant in the problem, the researcher asks the subject to write what is thought. The results of the subject's answers can be seen in Figure 1 as follows. 


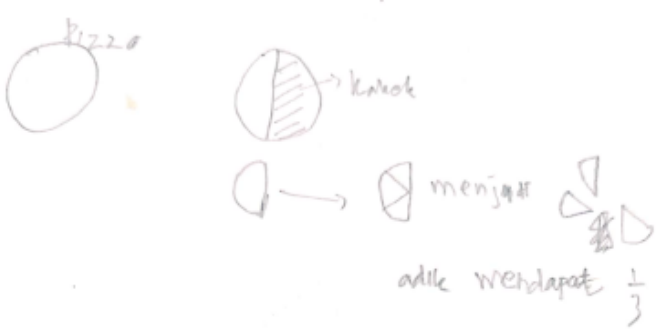

Figure 1. Answer the subject in solving problems

From the answers to the above subjects. The subject drew a circle named pizza. Then the subject gives a line in the middle of the circle that shows the pizza is divided into two and shades a part given to grandfather.

Researcher : What are the first steps you take to solve the problem?

Subject : I divide the pizza into two.

Researcher : why is pizza divided into two?

Subject : because half is given to the grandfather

Researcher : why is the other part divided by three?

Subject : would you like to be given Aqla's three siblings?

Researcher : How much does Aqla's sister get pizza?

Subject : The third part of the mam ...

Researcher : Why did Aqla's sister get the third part?

Subject : the pizza is divided into three

Researcher : Is there no relation to the pizza given to Grandfather?

Subject : hemmmmm ... yes yes ...

Researcher : Try to analyze again

Subject murmured: initially the pizza was divided into two, then the half was given to grandfather, the other half was given to three younger siblings. The subject was silent, then said: "I'm a confused mom ...". From this case, it can be seen that the subject ignored the pizza that was given to Grandfather. Half the pizza given to grandfather is missing from the subject's attention. Students fail to interpret the signs (pictures) that have been made.

\subsection{Discussion}

The results of the study showed that the subject failed to interpret the sign. In solving problems, the subject uses visual representation. Representations raised by the subject are expressions of mathematical ideas displayed by the subject to find a solution to the problem/problem that is being faced. This is in accordance with the opinion [7] which states that to solve a problem and understand understanding mathematical concepts students can use visual representations. One way to measure students' visual representations is based on their ability to plan, implement strategies to solve problems [22]. In solving problems the subject uses pictures. The subject creates geometric shapes to express his mathematical ideas. To be able to solve problems correctly, students must be able to interpret the signs that have been made [1].

In solving math problems, the subject's attention was lost to half the pizza that was given to Grandfather. After dividing the pizza into two parts, students do not pay attention to the pizza given to grandfather. The subject ignored the picture of the pizza given to Aqla's grandfather. The subject only paid attention to half of the portion that would be divided among the three Aqla sisters. The subject failed in interpreting the sign that was created. Interpretation is a response to the object through the interpretation of the sign [23], [24]. This causes the subject's answers to be incorrect. The loss of subject attention to the half pizza picture of students accustomed to being given instructions by the teacher in solving problems. This is contrary to the opinion [25] which states that in learning the teacher should give freedom of argument. In addition, in the learning process teachers should be able to increase student involvement so students are enthusiastic in learning. External stimuli can attract students' attention and can increase enthusiasm, improve student memory and focus student attention when following the learning process [26].

\section{Conclusion}

From the results of the study, showing the subject uses visual representation. The subject solved the problem using pictures. In disregarding the problem, the subject makes geometrical drawings that represent pizza and divides it into two parts. Half the portion was given to grandfather and half the portion was divided into three parts to be given to Aqla's sister. The steps taken by the subject in solving the problem are correct but the subject is wrong in drawing the final conclusion that each Aqla sister gets the third portion of pizza. Failure to interpret occurs when the research subject does not see the pizza picture given to Aqla's grandfather. The subject failed in interpreting the semiotic representation of a picture of half a pizza given to grandfather and half a pizza given to Aqla's three siblings. This happened 
because the subject ignored the pizza picture that was given to Aqla's grandfather. The loss of subject attention to the half pizza picture of students accustomed to being given instructions by the teacher in solving problems

\section{References}

[1] C. W. Suryaningrum, 'Why Do Students Make Errors when Solving Problem in Semiotic Representation?', Adv. Soc. Sci. Educ. Humanit. Res., vol. 218, no. ICoMSE 2017, pp. 8-11, 2017.

[2] M. H. G. Hoffmann, "What Is a " Semiotic Perspective ", and What Could It Be? Some Comments on the Contributions to This Special Issue', Educ. Stud. Math., vol. 61, no. 1, pp. 279-291, 2006.

[3] F. Stjernfelt, 'Dicisigns Peirce's semiotic doctrine of propositions', Synth. An Int. J. Epistemol. Methodol. Philos. Sci., vol. 192, no. 4, pp. 1019-1054, 2015

[4] C. Kralemann B, and Lattmann, 'Models as Icons : Modeling Models in The Semiotic Framework of Peirce's Theory of Signs', Synthese, vol. 190, no. 16, pp. 3397-3420, 2013.

[5] A. Minarni, E. E. Napitupulu, and R. Husein, 'Mathematical understanding and representation ability of public junior high school in North Sumatra', J. Math. Educ., 2016.

[6] A. P. Bal, 'The Examination of Representations used by Classroom Teacher Candidates in Solving Mathematical Problems', Educ. Sci. Theory Pract., vol. 14, no. 6, pp. 2349-2365, 2014.

[7] C. W. Suryaningrum and H. Susanto, 'Representation of Schematic Visual in Solving Pythagoras 'Wordproblems', vol. 01, no. 1, pp. 52-61, 2018 .

[8] M. Durkaya, E. Özge, M. F. Öçal, A. Kaplan, and Z. Aksu, 'Pre-service mathematics teachers' multiple representation competencies about determinant concept', Procedia Soc. Behav. Sci., vol. 15, pp. 2554-2558, 2011.

[9] L. Zhe, 'Survey of Primary Students ' Mathematical Representation Status and Study on the Teaching Model of Mathematical Representation', J. Math. Educ., vol. 5, no. 1, pp. 63-76, 2012.

[10] M. Chen and C. Lee, 'Influence of Mathematical Representation and Mathematics Self-Efficacy on the Learning Effectiveness of Fifth Graders in Pattern Reasoning', Int. J. Learn. Teach. Educ. Res., vol. 13, no. 1, pp. 1-16, 2015.

[11] G. Güler and A. Ciltas, 'The Visual Representation Usage Levels of Mathematics Teachers and Students in Solving Verbal Problems', Int. J. Humanit. Soc. Sci., vol. 1, no. 11, pp. 145-154, 2011.
[12] Suryaningrum and Ningtyas, 'Multiple Representations in Semiotic Reasoning', IOP Conf. Ser., vol. 1315, no. 012064, 2019 .

[13] NCTM, Principles and Standards for School Mathematics. VA: NCTM, 2000.

[14] J. L. Krawec, 'Problem Representation and Mathematical Problem Solving of Students of Varying Math Ability', $J$ Learn. Disabil., vol. 47, no. 2, pp. 103-115, 2014.

[15] O. Tarasenkova, N., Kovalenko, 'Content and Semiotic Features of Mathematical Problems Used as a Means of Training the Primary School Education Students', Am. J. Educ. Res., vol. 3, no. 12B, pp. 31-35, 2015.

[16] S. Ç. Uzun and S. Arslan, 'Semiotic representations skills of prospective elementary teachers related to mathematical concepts', Procedia - Soc. Behav. Sci., vol. 1, no. 1, pp. 741-745, 2009

[17] C. Schreiber, 'Semiotic Processes in Chat-Based ProblemSolving Situations', Educ Stud Math, vol. 82, pp. 51-73, 2013

18] R. Bjuland, 'The Mediating Role of a Teacher' $s$ Use of Semiotic Resources in Pupils' Early Algebraic Reasoning', ZDM Math. Educ., vol. 44, no. 5, pp. 665-675, 2012.

[19] J. W. Creswell, Educational Research: Planning, Conducting and Evaluating Quantitative and Qualitative Research. London: Pearson, 2012.

[20] A. K. Jitendra, M. P. George, S. Sood, and K. Price, 'Schema-Based Instruction: Facilitating Mathematical Word Problem Solving for Students with Emotional and Behavioral Disorders.', Prev. Sch. Fail., vol. 54, no. 3, pp. 145-151, 2010

[21] E. E. Kribbs and B. A. Rogowsky, 'International Journal of Research in Education and Science (IJRES) A Review of the Effects of Visual-Spatial Representations and Heuristics on Word Problem Solving in Middle School Mathematics A Review of the Effects of Visual-Spatial Representations and', Int. J. Res. Educ. Sci., vol. 2, no. 1, pp. 65-74, 2016.

[22] E. Surya, J. Sabandar, Y. S. Kusumah, and Darhim, 'Improving of Junior High School Visual Thingking Representation Ability in Mathematical Problem Solving by CTL', IndoMS. J.M.E, vol. 4, no. 1, pp. 113-126, 2013.

[23] U. Eco, A Theory of Semiotics. Bloomington: Indiana: Indiana University, 1976.

[24] U. Eco, The Role of the Reader Explorations in the Semiotics of Texts. Bloomington: Indianan University press, 1984.

[25] F. Arzarello and C. Sabena, 'Semiotic and theoretic control in argumentation and proof activities', Educ. Stud. Math. vol. 77, no. 2-3, pp. 189-206, 2011.

[26] E. Rosegard and J. Wilson, 'Capturing students' attention : An empirical study', J. Scholarsh. Theaching Learn., vol. 13 , no. 5, pp. 1-20, 2013. 